\title{
Penoscrotal Transposition: A Case Report
}

\author{
S. D. Naren • C. Soren • P. V. Subbarao
}

Received: 8 December 2011 / Accepted: 7 March 2012 /Published online: 16 March 2012

(C) Association of Surgeons of India 2012

Penoscrotal transposition (PST) is an extremely rare congenital malformation, usually associated with a wide variety of other anomalies. We describe an exceptional case of a newborn with PST, but normal upper urinary tract and no other associated malformations.

An unbooked newborn male delivered at term with no reported antenatal complications. There was no evidence of mother being exposed to teratogens during pregnancy. On physical examination, an abnormal appearance of the external genitalia could be seen. There was a complete rotation of the external genitalia with cryptorchidism. Penis with chordee was noted (Fig. 1). Urinalysis, renal and vesical sonography, and voiding cystourethrography showed no other urological abnormalities. There were no associated cardiological or gastrointestinal anomalies.

PST is a very uncommon heterogeneous condition in which the scrotum is positioned superior and anterior to the penis. Less than 20 cases of extreme degree of PST with normal scrotum have been reported in the literature [1]. PST

Concept and design by Dr Naren, drafting the article by Dr Soren and final approval of the version to be published by Dr Subbarao.

S. D. Naren $(\bowtie) \cdot$ C. Soren $\cdot$ P. V. Subbarao

Paediatrics, Konaseema Institute of Medical Sciences,

Chaitanya Nagar, Amalapuram,

East Godavari dist, Andhra Pradesh 533201, India

e-mail: dudyalanaren@rediffmail.com results from abnormal genital tubercle development around the 6th week of gestation. It is associated with delay in the midline fusion of the urethral folds. Although the occurrence of most reported cases of PST has been sporadic, other congenital anomalies such as hypospadias, chordee, and renal agenesis or dysplasia could be found in approximately $90 \%$ of patients [2]. Gastrointestinal abnormalities, predominantly imperforate anus, were found in $30 \%$ of cases [3]. PST may present with a broad spectrum of abnormalities ranging from simple shawl scrotum (doughnut scrotum) to very complex extreme transposition with cardiac, gastrointestinal, craniofacial, central nervous system, genital, and urological malformations [4]. Growth deficiency and mental retardation have also been noticed in $60 \%$ of patients [5]. Differential diagnosis must include pseudohermaphroditism, penoscrotal hypospadias, micropenis, intrauterine penile amputation, and especially penile agenesis with a midline skin tag anterior to the anus. Complete penoscrotal transpositions have been rarely reported in the Indian literature [6]. Surgery in more complex cases of PST is technically challenging. It is usually performed between 12 18 months. The size of the phallus and its potential to develop at puberty into a sexually satisfactory penis are of paramount relevance when surgery is planned. In order to assess this situation, a surgeon must carefully palpate the corporal bodies to determine their bulk and sometimes perform a testosterone test to demonstrate erections. Extreme 


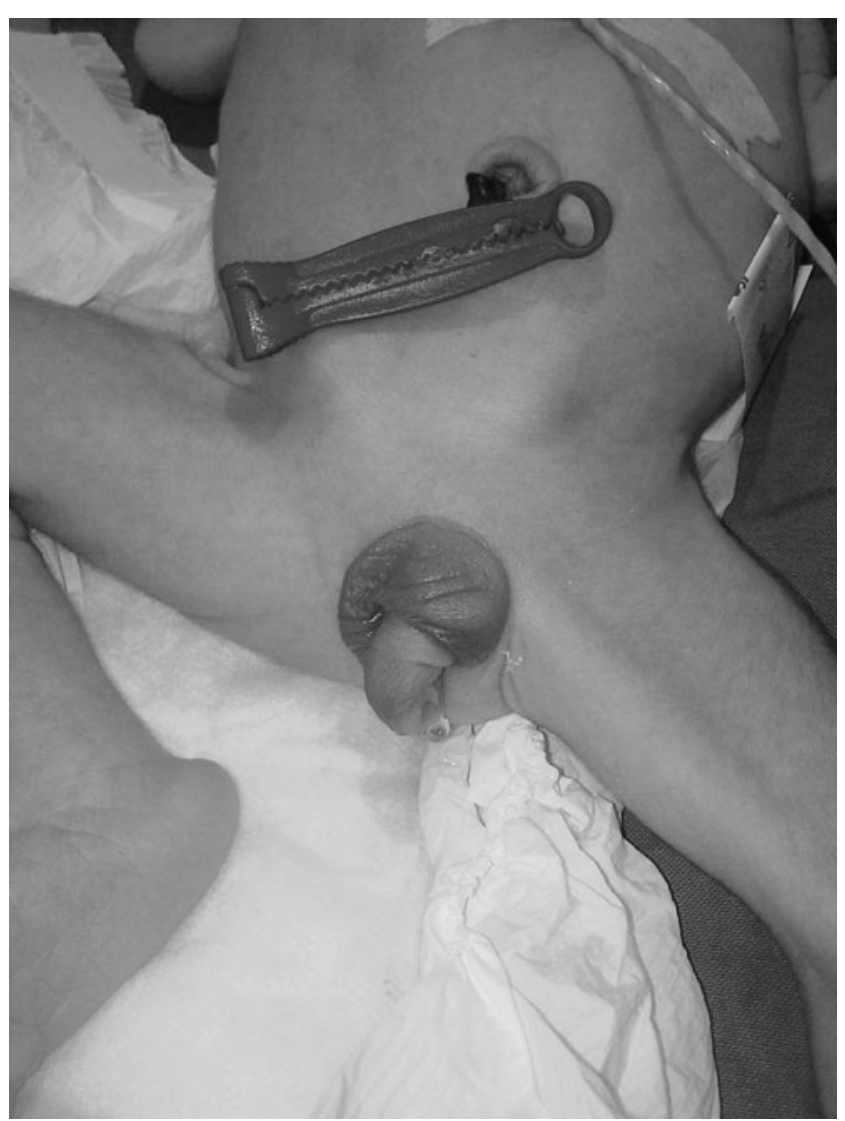

Fig. 1 Complete penoscrotal transposition penoscrotal transposition with severe hypospadias and chordee is difficult to differentiate from penile agenesis with a midline skin tag anterior to the anus (with penile atrophic body buried in the perineum). In both cases the penile reconstruction and repositioning are often unsatisfactory, and female gender reassignment, while ethically controversial, may be a prudent therapeutic in selected cases.

\section{Source of funding None}

\section{References}

1. Cohen-Addad N, Zarafu IW, Hanna MK (1985) Complete penoscrotal transposition. Urology 26:149-152

2. Pinke LA, Rathbun SR, Husmann DA, Kramer SA (2001) Penoscrotal transposition: review of 53 patients. J Urol 166:18651868

3. Buyukkayhan D, Kurtoglu S, Koklu E, Hatipoglu N, Akcakus M (2007) Complete penoscrotal transposition associated with aortic stenosis in a newborn. J Pediatr Endocrinol Metab 20:881

4. Meguid NA, Temtamy SA, Mazen I (2003) Transposition of external genitalia and associated malformations. Clin Dysmorphol 12:59-62

5. MacKenzie J, Chitayat D, McLorie G, Balfe JW, Pandit PB, Blecher SR (1994) Penoscrotal transposition: a case report and review. Am J Med Genet 49:103-107

6. Kain R, Arulprakash S (2005) Complete penoscrotal transposition. Indian Pediatr 42:718 